\title{
Post-traumatic Stress and Related Factors Among Hospital Nurses during the COVID-19 Outbreak in Korea
}

\author{
Da-Jeong Moon ${ }^{1,2}$ (D) Mi Ah Han ${ }^{3}$ (D) Jong Park ${ }^{3}$ (D) . So Yeon Ryu
}

Accepted: 21 March 2021/ Published online: 31 March 2021

(c) The Author(s), under exclusive licence to Springer Science+Business Media, LLC, part of Springer Nature 2021

\begin{abstract}
COVID-19 is an ongoing worldwide infectious disease pandemic. The purpose of this study was to investigate post-traumatic stress and related factors among hospital nurses during the COVID-19 outbreak. The subjects of this study were 300 nurses who worked in three general hospitals that operated National Designated Isolation Unit (NDIU) wards during the COVID-19 outbreak. Self-reporting questionnaires were used to collect data on post-traumatic stress, general characteristics, and work-related information. The average post-traumatic stress score was $20.68 \pm 19.5$ points and $36.7 \%$ of participants were at high risk of post-traumatic stress disorder (PTSD). The odds ratio (OR) for PTSD was higher for nurses who worked in the NDIU ward $(\mathrm{OR}=16.31,95 \% \mathrm{CI}=3.79-70.32)$, who responded that nurse staffing was poor $(\mathrm{OR}=3.03,95 \% \mathrm{CI}=1.01-9.10)$, and who responded that they experienced COVID-19 symptoms $(\mathrm{OR}=3.83,95 \% \mathrm{CI}=1.89-7.75)$. Total $36.7 \%$ of nurses were at risk of PTSD and the factors related to PTSD were the work department, nurse staffing, and experiencing COVID-19 symptoms. These results could be used to manage PTSD and provide psychological support of nurses during infectious disease epidemics, such as COVID-19.
\end{abstract}

Keywords COVID-19 $\cdot$ Nurses $\cdot$ Disease outbreaks $\cdot$ Post-traumatic stress disorders

\section{Introduction}

COVID-19 is an infectious respiratory disease caused by a new coronavirus, SARS-CoV-2, that has been occurring worldwide, including Korea, since its first outbreak in December 2019 in Wuhan, China [1]. As of January 2021, the cumulative confirmed cases of

This article is a condensed form of the first author's master's thesis from Chosun University.

Mi Ah Han

mahan@chosun.ac.kr

1 Department of Public Health, Graduate School of Health Science, Chosun University, Gwangju, Republic of Korea

2 Department of Nursing, Chosun University Hospital, Gwangju, Republic of Korea

3 Department of Preventive Medicine, College of Medicine, Chosun University, 309 Philmum-daero, Dong-gu, Gwangju 61452, Republic of Korea 
COVID-19 worldwide were more than 93 million with over 2 million deaths [2]. In Korea, the first confirmed case was reported on January 20, 2020, and gradually spread nationwide with more than 70,000 confirmed cases and $~ 1,300$ deaths by January 2021 [3]. Although exact numbers have not been reported, the COVID-19 pandemic has caused many deaths of health care workers, including nurses and doctors [4].

Previous studies reported that healthcare workers are at high risk of post-traumatic stress disorder (PTSD) due to new infectious diseases, such as Sever Acute Respiratory Syndrome (SARS) [5]. At two months post-SARS outbreak, the prevalence of PTSD was $\sim 20 \%$ and support from supervisors and colleagues associated negatively with PTSD in healthcare workers [6]. In addition to post-traumatic stress, healthcare workers experienced high levels of distress, and nurses reported severe stress due to the SARS outbreak [7]. During the Middle East Respiratory Syndrome (MERS) epidemic, post-traumatic stress among nurses associated significantly with contact with suspected and confirmed MERS patients, work position, shift work [8], and support from supervisors [9].

During the recent COVID-19 pandemic, healthcare workers have experienced significantly higher levels of post-traumatic stress (28.9\%), and the post-traumatic stress levels have been higher among healthcare workers who directly care for COVID-19 patients than among healthcare workers who care for COVID-19 patients indirectly [10]. The prevalence of depression (34.3\%) and anxiety (18.1\%) among nurses during the COVID-19 outbreak has been high, and COVID-19-related stress and psychological factors have affected the mental health of nurses [11]. Among the medical staff, nurses have reported more severe psychiatric symptoms and worse sleep quality [12].

The World Health Organization (WHO) has classified COVID-19 as a pandemic, and the outbreak has been ongoing in Korea from January 2020-January 2021. Due to the nature of their work, nurses could not telework, cared for sick people, and remained anxious that they may be infected with COVID-19. Therefore, we investigated the current status of post-traumatic stress and related factors in nurses at COVID-19 treatment hospitals.

\section{Materials and Methods}

\section{Study Population}

The study population included nurses who worked at three hospitals, C University Hospital in Gwangju, W University Hospital, and G Medical Center in Jeollabukdo, that operate National Designated Isolation Unit wards (NDIUs). With cooperation from the Department of Nursing, nurses who worked during the COVID-19 outbreak were sampled. We excluded nurses who did not care for patients directly, such as nurses who worked on the quality improvement and health insurance review teams. We collected data using selfadministered questionnaires and informed consent was obtained from all participants. The survey was conducted from September 3 to September 16, 2020, and a total of 300 nurses participated.

\section{General Characteristics}

General characteristics included sex (men, women), age (20-29, $\geq 30$ years), marital status (single, married), children (no, yes), education level (college, university, graduate school), work period ( $<5, \geq 5$ years), working position (staff nurse, charge/senior nurse), working 
department (NDIU, general ward, intensive care unit, other), monthly salary $(<3$ million, $\geq 3$ million Korean won), and living status (live alone, live together).

\section{Work Environment during the COVID-19 Outbreak}

The work environment included perceived level of ambient noise from the environment, such as patient monitoring devices, call bells, negative pressure machine (little, moderate, a lot), break time during work $(<30, \geq 30 \mathrm{~min})$, overtime work $(<30, \geq 30 \mathrm{~min})$, nursing workload (low, moderate, high), nurse staffing (poor, fair, good), adequate provision of personal protective equipment, such as dental mask, N95 mask, protective clothing (yes, no/ don't know), frequency of changes to COVID-19 guidelines (no/occasionally, moderate, frequently), support from supervisors (low, moderate, high), and support from colleagues (low, moderate, high).

\section{Covid-19-Related Characteristics}

COVID-19-related characteristics included presence of COVID-19 suspected symptoms (no, yes), COVID-19 test performed (no, yes), self-isolation or isolation of family members (no, yes), subjective level of COVID-19 related knowledge (little, average, knowledgeable), education of new infectious diseases (no, yes), and nursing care for suspected and confirmed COVID-19 patients (no, yes).

Among nurses who cared for suspected and confirmed COVID-19 patients, the data collected included the number of times they wore protective clothing $(0-10, \geq 11$ times), the amount of time per day protective clothing was worn $(<2, \geq 2 \mathrm{~h})$, the tightness of the protective clothing (little, moderate, a lot), the number of critical patients they cared for $(0$, $1-2, \geq 3$ ), and whether they cared for patients who died (no, yes).

\section{Post-Traumatic Stress}

Post-traumatic stress was assessed using the Korean version of the Impact of Event ScaleRevised (IES-R) tool [13]. The tool uses a five-point Likert scale (0-4) for 22 questions on hyperarousal (6 questions), avoidance (6 questions), intrusion (5 questions), and sleep $\&$ numbness (5 questions). How often these symptoms appeared during the COVID-19 outbreak period were assessed; 0 points were allotted for "not at all" responses and 4 were allotted for "very much" responses, and the higher the score, the higher the post-traumatic stress. Out of a maximum of 88 points, individuals with scores of 24 points or less were designated to the normal group and individuals with scores of 25 points or more were designated to the PTSD group.

\section{Analysis}

Data were analyzed using the statistical program SPSS version 26. The general characteristics of the study population, work environment, and COVID-19-related characteristics were presented as frequencies and percentages, whereas the post-traumatic stress scores were presented as mean \pm standard deviation. The chi-square test was used to assess the prevalence of PTSD based on general characteristics, work environment, and COVID-19 
characteristics. To identify the factors associated with PTSD, we performed multiple logistic regression analysis. $\mathrm{p}<0.05$ indicated statistical significance.

\section{Results}

The average post-traumatic stress score was $20.68 \pm 19.50$, and $36.7 \%$ of the nurses evaluated were in the high-risk of PTSD group (scores $\geq 25$ points). The prevalence of PTSD was $30.4 \%$ for nurses aged $20-29$ years, $46.2 \%$ for nurses aged $\geq 30$ years, $47.7 \%$ for nurses with children, and $33.6 \%$ for nurses without children. The prevalence of PTSD was $31.6 \%$ for nurses who worked $<5$ years and $45.5 \%$ for nurses who worked $>5$ years. The prevalence of PTSD was $63.3 \%$ for nurses who worked in the NDIU ward, $30.2 \%$ for nurses who worked in the general ward, $39.6 \%$ for nurses who worked in the intensive care unit, and $21.1 \%$ for nurses who worked in other departments (Table 1).

Regarding the work environment, the prevalence of PTSD was $22.8 \%$ when there was little noise in the surrounding environment, $35.8 \%$ with moderate noise, and $48.7 \%$ with a lot of noise. The prevalence of PTSD was $20.0 \%$ when the workload was low, $30.3 \%$

Table 1 General characteristics and post-traumatic stress disorder

\begin{tabular}{|c|c|c|c|c|c|}
\hline \multirow[t]{2}{*}{ Characteristics } & \multirow[t]{2}{*}{ Classification } & \multirow[b]{2}{*}{ Total } & \multicolumn{2}{|l|}{ PTSD } & \multirow[t]{2}{*}{$P$} \\
\hline & & & Yes & No & \\
\hline \multirow[t]{2}{*}{ Sex } & Men & $7(2.3)$ & $4(57.1)$ & $3(42.9)$ & 0.255 \\
\hline & Women & 293(97.7) & $106(36.2)$ & $187(63.8)$ & \\
\hline \multirow[t]{2}{*}{ Age } & $20-29$ & $181(60.3)$ & $55(30.4)$ & $126(69.6)$ & 0.005 \\
\hline & $\geq 30$ & 119(39.7) & $55(46.2)$ & $64(53.8)$ & \\
\hline \multirow[t]{2}{*}{ Marital status } & Single & $221(73.7)$ & $75(33.9)$ & $146(66.1)$ & 0.101 \\
\hline & Married & $79(26.3)$ & $35(44.3)$ & $44(55.7)$ & \\
\hline \multirow[t]{2}{*}{ Children } & Yes & $235(78.3)$ & $31(47.7)$ & $34(52.3)$ & 0.037 \\
\hline & No & $65(21.7)$ & $79(33.6)$ & $156(66.4)$ & \\
\hline \multirow[t]{3}{*}{ Education level } & College & $32(10.7)$ & $15(46.9)$ & $17(53.1)$ & 0.320 \\
\hline & University & $250(83.3)$ & $87(34.8)$ & $163(65.2)$ & \\
\hline & Graduate school & $18(6.0)$ & $8(44.4)$ & $10(55.6)$ & \\
\hline \multirow[t]{2}{*}{ Work period (years) } & $<5$ & $190(63.3)$ & $60(31.6)$ & $130(68.4)$ & 0.016 \\
\hline & $\geq 5$ & $110(36.7)$ & $50(45.5)$ & $60(54.5)$ & \\
\hline \multirow[t]{2}{*}{ Working position } & Staff nurse & $278(92.7)$ & $98(35.3)$ & $180(64.7)$ & 0.071 \\
\hline & Charge/senior nurse & $22(7.3)$ & $12(54.5)$ & $10(45.5)$ & \\
\hline \multirow[t]{4}{*}{ Working department } & $\begin{array}{l}\text { National Designated } \\
\text { Isolation Unit wards }\end{array}$ & $49(16.3)$ & $31(63.3)$ & $18(36.7)$ & 0.000 \\
\hline & General wards & $179(59.7)$ & $54(30.2)$ & $125(69.8)$ & \\
\hline & Intensive care units & $53(17.7)$ & $21(39.6)$ & $32(60.4)$ & \\
\hline & Others & $19(6.3)$ & $4(21.1)$ & $15(78.9)$ & \\
\hline \multirow[t]{2}{*}{ Salary (Korean won/month) } & $<3$ million & $209(69.7)$ & $68(32.5)$ & $141(67.5)$ & 0.024 \\
\hline & $\geq 3$ million & $91(30.3)$ & $42(46.2)$ & $49(53.8)$ & \\
\hline \multirow[t]{2}{*}{ Living status } & Live alone & $50(16.7)$ & $13(26.0)$ & $37(74.0)$ & 0.086 \\
\hline & Live together & $250(83.3)$ & $97(38.8)$ & $153(61.2)$ & \\
\hline
\end{tabular}

Data were expressed as number (\%). PTSD, post-traumatic stress disorder 
when the workload was moderate, and $45.2 \%$ when the workload was high. The prevalence of PTSD was $37.6 \%$ when nurse staffing was poor, $41.9 \%$ when nurse staffing was fair, and $14.3 \%$ when nurse staffing was good. The prevalence of PTSD was $26.2 \%$ when the COVID-19 work guidelines had not changed or changed only a little, $34.2 \%$ when there were moderate changes to the guidelines, and $44.9 \%$ when there were frequent changes in the guidelines (Table 2).

The prevalence of PTSD was 58.1\% when nurses experienced COVID-19 symptoms and $31.1 \%$ when COVID-19 symptoms were not experienced. The prevalence of PTSD was $42.3 \%$ among nurses educated on new infectious diseases and $29.5 \%$ among nurses who were not educated on new infectious diseases. The prevalence of PTSD was $26.8 \%$ for nurses who cared for suspected and confirmed COVID-19 patients, 26.8\% for nurses who wore protective clothing less than 10 times, and $47.9 \%$ for nurses who wore protective clothing more than 11 times. The prevalence of PTSD was $19.1 \%$ for nurses who wore protective clothing less than $2 \mathrm{~h}$ per occasion and $72.7 \%$ for nurses who wore protective clothing for more than $2 \mathrm{~h}$. The prevalence of PTSD was $20.9 \%$ for nurses who had no critical patients, $31.3 \%$ for nurses with 1-2 critical patients, and $70.3 \%$ for nurses with 3 or more

Table 2 Work environment during COVID-19 outbreak and post-traumatic stress disorder

\begin{tabular}{|c|c|c|c|c|c|}
\hline \multirow[t]{2}{*}{ Characteristics } & \multirow[t]{2}{*}{ Classification } & \multirow[b]{2}{*}{ Total } & \multicolumn{2}{|l|}{ PTSD } & \multirow[t]{2}{*}{$P$} \\
\hline & & & Yes & No & \\
\hline \multirow[t]{3}{*}{ Ambient noise } & Little & $57(19.0)$ & $13(22.8)$ & $44(77.2)$ & 0.008 \\
\hline & Moderate & $165(55.0)$ & $59(35.8)$ & $106(64.2)$ & \\
\hline & A lot & $78(26.0)$ & $38(48.7)$ & $40(51.3)$ & \\
\hline \multirow[t]{2}{*}{ Break time during work (minutes) } & $<30$ & $196(65.3)$ & $77(39.3)$ & $119(60.7)$ & 0.196 \\
\hline & $\geq 30$ & $104(34.7)$ & $33(31.7)$ & $71(68.3)$ & \\
\hline \multirow[t]{2}{*}{ Overtime work (minutes) } & $<30$ & $168(56.0)$ & $58(34.5)$ & $110(65.5)$ & 0.385 \\
\hline & $\geq 30$ & $132(44.0)$ & $52(39.4)$ & $80(60.6)$ & \\
\hline \multirow[t]{3}{*}{ Nursing workload } & Low & $10(3.3)$ & $2(20.0)$ & $8(80.0)$ & 0.017 \\
\hline & Moderate & $155(51.7)$ & $47(30.3)$ & $108(69.7)$ & \\
\hline & High & $135(45.0)$ & $61(45.2)$ & $74(54.8)$ & \\
\hline \multirow[t]{3}{*}{ Nurse staffing } & Poor & $109(36.3)$ & $41(37.6)$ & $68(62.4)$ & 0.009 \\
\hline & Fair & $148(49.3)$ & $62(41.9)$ & $86(58.1)$ & \\
\hline & Good & $43(14.3)$ & $7(16.3)$ & $36(83.7)$ & \\
\hline \multirow{2}{*}{$\begin{array}{l}\text { Adequate provision of personal protective } \\
\text { equipment }\end{array}$} & Yes & $197(65.7)$ & $69(35.0)$ & $128(65.0)$ & 0.415 \\
\hline & No/don't know & $103(34.3)$ & $41(39.8)$ & $62(60.2)$ & \\
\hline \multirow[t]{3}{*}{ Changing frequency to COVID-19 guidelines } & No/occasionally & $65(21.7)$ & $17(26.2)$ & $48(73.8)$ & 0.032 \\
\hline & Moderate & $117(39.0)$ & $40(34.2)$ & $77(65.8)$ & \\
\hline & Frequently & $118(39.3)$ & $53(44.9)$ & $65(55.1)$ & \\
\hline \multirow[t]{3}{*}{ Support from supervisors } & Low & $11(3.7)$ & $5(45.5)$ & $6(54.5)$ & 0.760 \\
\hline & Moderate & $155(51.7)$ & $58(37.4)$ & $97(62.6)$ & \\
\hline & High & 134(44.7) & $47(35.1)$ & $87(64.9)$ & \\
\hline \multirow[t]{3}{*}{ Support from colleagues } & Low & $7(2.3)$ & $3(42.9)$ & $4(57.1)$ & 0.897 \\
\hline & Moderate & $124(41.3)$ & $44(35.5)$ & $80(64.5)$ & \\
\hline & High & $169(56.3)$ & $63(37.3)$ & $106(62.7)$ & \\
\hline
\end{tabular}

Data were expressed as number (\%). PTSD, post-traumatic stress disorder 
critical patients. The prevalence of PTSD was $63.3 \%$ for nurses who had patients who died and $22.2 \%$ for nurses who did not have patients who died (Table 3).

Multiple logistic regression analysis showed that the adjusted odd ratio (AOR) for PTSD was higher for nurses working in the NDIU ward than for nurses working in the general ward $(\mathrm{OR}=2.85,95 \% \mathrm{CI}=1.21-6.71)$. The AOR for PTSD was higher for nurses who responded that nurse staffing was poor $(\mathrm{OR}=3.03,95 \% \mathrm{CI}=1.01-9.10)$ or fair $(\mathrm{OR}=4.10$, $95 \% \mathrm{CI}=1.47-11.46)$ than for nurses who responded that nurse staffing was good. Experiencing COVID-19 symptoms associated with a higher risk of PTSD (OR =3.83, 95\% $\mathrm{CI}=1.89-7.75$; Table 4).

\section{Discussion}

We investigated the prevalence of PTSD and related factors among nurses. Overall, 36.7\% of nurses were at high risk of PTSD. Working in the NDIU ward, experiencing poor nurse staffing, and experiencing COVID-19 symptoms associated with a higher risk of PTSD. In this study during the COVID-19 outbreak, the mean post-traumatic stress score was $20.68 \pm 19.50$ points out of a maximum of 88 points, and $36.7 \%$ of the nurses had scores $\geq 25$ points and were in the high risk of PTSD.

Among front-line nurses in the Philippines, 37.8\% were found to have dysfunctional levels of COVID-10-related anxiety [14]. In a cross-sectional study, 64\% of nurses experienced acute stress disorder due to the COVID-19 pandemic and were at risk for PTSD [15]. A study measuring post-traumatic stress among nurses after the MERS outbreak in Korea used the same IES-R tool and showed that the mean PTSD score was $7.80 \pm 10.15$ with 7.1\% of nurses at high risk of PTSD [8]. A study that addressed psychological distress during SARS outbreaks showed that $11 \%$ of nurses experienced the stress reaction syndrome [16]. The higher PTSD score in this study is due to the higher numbers of infections and deaths from COVID-19 than MERS and SARS. During the SARS outbreaks, there were 8,096 infections worldwide (3 in Korea) and 774 deaths (0 in Korea). During the MERS outbreak, there were 1,167 infections worldwide (186 in Korea) and 479 deaths (38 in Korea) [17]. Currently, more than 93 million people worldwide have been infected with COVID-19 and more than 2 million people worldwide have died from COVID-19. In addition, the number of confirmed COVID-19 cases continues to increase.

In this study, we found that the work department associated with the risk of PTSD. The OR for PTSD was significantly higher for nurses who worked in the NDIS ward than for nurses who worked in the general ward. In the NDIS ward, nurses directly cared for suspected and confirmed COVID-19 patients and had to perform new tasks, including wearing protective clothing, adhering to strict infection control guidelines, and working long hours in full-body suits [18]. Because nurses in the NDIS ward directly care for COVID-19 patients, their risk of infection and psychological burden was high.

In this study, the experience of caring for suspected and confirmed COVID-19 patients did not associate with PTSD. In a prior study of nurses during the MERS outbreak, the experience of caring for suspected and confirmed MERS patients was a significant factor for PTSD [8]. In addition, post-traumatic stress scores were higher for nurses who were in contact with SARS patients than for nurses who were not in contact with SARS patients [6]. Perhaps the prolonged outbreak of COVID-19 led to nurses becoming accustomed to patients with COVID-19 and reduced awareness and fear. 


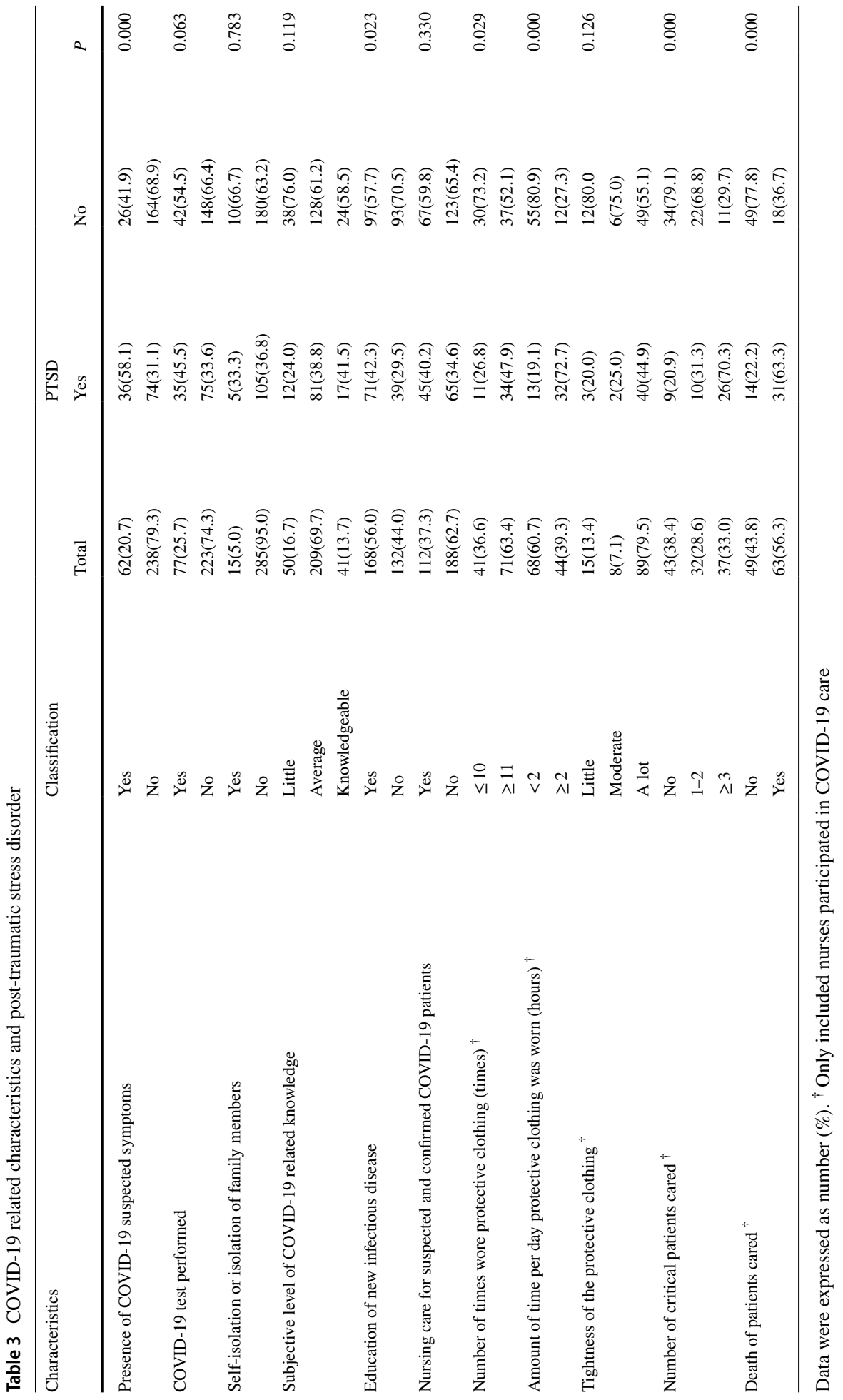


In this study, the OR for PTSD was significantly higher for nurses who responded that nurse staffing was poor and fair than for nurses who responded that nurse staffing was good. When nurse staffing is inadequate, nurses care for numerous patients and have a high workload. Previous studies showed that the more patients in a nurse's care, the higher the stress on the nurse [19], and chronic exposure to stress associates significantly with PTSD [20]. The number of hours worked per week associated significantly with stress among nurses during the COVID-19 outbreak in Wuhan, China [21]. In addition, an increase in the number of patients was shown to increase burnout and decrease job satisfaction among nurses [22]. The number of patients per nurse is higher in the NDIU ward than in other departments because the minimum number of nurses are assigned alternately to minimize contacts with confirmed patients. Further, due to the nature of infectious diseases, it is difficult to predict the number and severity of infectious diseases, which likely increases psychological pressure.

Table 4 Factors related to post-traumatic stress disorder

\begin{tabular}{|c|c|c|c|}
\hline Characteristics & Classification & OR & $95 \% \mathrm{CI}$ \\
\hline \multirow[t]{2}{*}{ Age } & $20-29$ & 1.00 & \\
\hline & $\geq 30$ & 1.44 & $0.57-3.61$ \\
\hline \multirow[t]{2}{*}{ Children } & Yes & 1.38 & $0.60-3.17$ \\
\hline & No & 1.00 & \\
\hline \multirow[t]{2}{*}{ Work period } & $<5$ & 1.00 & \\
\hline & $\geq 5$ & 1.19 & $0.42-3.37$ \\
\hline \multirow[t]{4}{*}{ Working department } & $\begin{array}{l}\text { National Designated Isola- } \\
\text { tion Unit wards }\end{array}$ & 2.85 & $1.21-6.71$ \\
\hline & General ward & 1.00 & \\
\hline & Intensive care units & 1.47 & $0.71-3.04$ \\
\hline & Others & 0.17 & $0.04-0.68$ \\
\hline \multirow[t]{2}{*}{ Salary (10,000won/month) } & $<300$ & 1.03 & $0.41-2.55$ \\
\hline & $\geq 300$ & 1.00 & \\
\hline \multirow[t]{3}{*}{ Ambient noise } & Little & 1.00 & \\
\hline & Moderate & 2.11 & $0.95-4.65$ \\
\hline & A lot & 1.72 & $0.70-4.22$ \\
\hline \multirow[t]{3}{*}{ Nursing workload } & Low & 1.00 & \\
\hline & Moderate & 1.59 & $0.25-10.16$ \\
\hline & High & 3.62 & $0.51-25.58$ \\
\hline \multirow[t]{3}{*}{ Nurse staffing } & Poor & 3.03 & $1.01-9.10$ \\
\hline & Fair & 4.10 & $1.47-11.46$ \\
\hline & Good & 1.00 & \\
\hline \multirow[t]{3}{*}{ Frequency of changes to COVID-19 guidelines } & No/occasionally & 1.00 & \\
\hline & Moderate & 1.52 & $0.71-3.28$ \\
\hline & Frequently & 2.14 & $0.99-4.62$ \\
\hline \multirow[t]{2}{*}{ Education of new infectious disease } & Yes & 1.68 & $0.87-3.25$ \\
\hline & No & 1.00 & \\
\hline \multirow[t]{2}{*}{ Presence of COVID-19 suspected symptoms } & Yes & 3.83 & $1.89-7.75$ \\
\hline & No & 1.00 & \\
\hline
\end{tabular}

$C I$ Confidence interval, $O R$ Odds ratio, $P T S D$ post-traumatic stress disorder 
The OR for PTSD was significantly higher for nurses who responded that they had COVID-19 symptoms than for nurses who did not have COVID-19 symptoms. An Australian study conducted during the COVID-19 outbreak revealed concern for work-related risks, such as an insufficient supply of personal protective equipment, that may cause nurses to quit their jobs [23]. There has been a worldwide shortage of personal protective equipment, and many medical professionals have died of COVID-19 [24]. Therefore, when nurses who cared for patients on the frontline experienced symptoms of COVID-19, such as fever, cough, and phlegm, their post-traumatic stress likely increased because they suspected that they may be infected with COVID-19.

Among nurses who treated COVID-19 patients, more instances and longer periods of wearing protective clothing associated with a higher risk of PTSD. An essential component of level D protective clothing is the N95 face mask. A previous study showed that wearing the N95 face mask may lead to headaches and that wearing the N95 masks for shorter durations may reduce the headaches [25]. A situation in which a nurse is in physical pain but cannot take off their protective clothing due to caring for a patient may lead to mental stress. In addition, the higher number of critically ill patients a nurse cares for and death of a patient associated with a high risk of PTSD. A previous study reported that intensive care nurses have a higher prevalence of PTSD than nurses in general wards [26]. Due to the nature of COVID-19 care, it is difficult to rearrange or replace nursing personnel frequently, thus post-traumatic stress management is necessary for nurses who take care of COVID-19 patients.

A limitation of this study was that it was conducted in only three hospitals in Korea, thus it is difficult to expand the interpretation to nurses across the entire country. Because data were collected using self-reporting surveys, some data may be over-reported or underreported. However, this study is meaningful in that it provides the current PTSD status and the factors related to PTSD among frontline nurses caring for COVID-19 patients, thus these data can be used to manage post-traumatic stress among nurses during future infectious disease outbreaks.

A total of $36.7 \%$ of the nurses in this study were at risk of PTSD. Working in NDIU wards, inadequate nurse staffing, and experiencing COVID-19 symptoms associated with PTSD. Further studies on personal or hospital level interventions for post-traumatic stress prevention or management, such as shift work for nurses, will help manage PTSD among nurses.

Authors' Contributions Conceptualization: Da-Jeong Moon, Mi Ah Han, Jong Park, So Yeon Ryu. Methodology: Da-Jeong Moon, Mi Ah Han, Jong Park, So Yeon Ryu. Formal analysis: Da-Jeong Moon, Mi Ah Han. Investigation: Da-Jeong Moon, Mi Ah Han. Data curation: Da-Jeong Moon, Mi Ah Han. Original draft preparation: Da-Jeong Moon, Mi Ah Han. Review: Da-Jeong Moon, Mi Ah Han, Jong Park, So Yeon Ryu. Editing: Da-Jeong Moon, Mi Ah Han, Jong Park, So Yeon Ryu.

Data Availability Not applicable.

Code Availability Not applicable.

\section{Declarations}

Ethics Approval This study was approved by the Institutional Review Board of Chosun University Hospital (CHOSUN2020-06-017-001).

Consent to Participate Informed consent was obtained from all participants. 
Consent for Publication Not applicable.

Conflicts of Interest/Competing Interests The authors have no potential conflicts of interest to disclose.

\section{References}

1. Lai CC, Shih TP, Ko WC, Tang HJ, Hsueh PR. Severe acute respiratory syndrome coronavirus 2 (SARS-CoV-2) and coronavirus disease-2019 (COVID-19): The epidemic and the challenges. Int J Antimicrob Agents. 2020;55(3):105924. https://doi.org/10.1016/j.ijantimicag.2020.105924.

2. World Health Organization. Weekly epidemiological update - 19 January 2021. 2021. https://www. who.int/publications/m/item/weekly-epidemiological-update---19-january-2021. Accessed 21 Jan 2021.

3. Korea Disease Control and Prevention Agency. Coronavirus Disease-19, Republic of Korea. 2021. http://ncov.mohw.go.kr/tcmBoardView.do?brdId=3\&brdGubun=31\&dataGubun=\&ncvContSeq= 4663\&contSeq=4663\&board_id=312\&gubun=ALL. Accessed 21 Jan 2021.

4. Jackson D, Anders R, Padula WV, Daly J, Davidson PM. Vulnerability of nurse and physicians with COVID-19: Monitoring and surveillance needed. J Clin Nurs. 2020;29(19-20):3584-7. https://doi.org/ 10.1111/jocn.15347.

5. Mak IW, Chu CM, Pan PC, Yiu MG, Chan VL. Long-term psychiatric morbidities among SARS survivors. Gen Hosp Psychiatry. 2009;31(4):318-26. https://doi.org/10.1016/j.genhosppsych.2009.03.001.

6. Chan AO, Huak CY. Psychological impact of the 2003 severe acute respiratory syndrome outbreak on health care workers in a medium size regional general hospital in Singapore. Occup Med (Lond). 2004;54(3):190-6. https://doi.org/10.1093/occmed/kqh027.

7. Maunder R. The experience of the 2003 SARS outbreak as a traumatic stress among frontline healthcare workers in Toronto: lessons learned. Philos Trans R Soc Lond B Biol Sci. 2004;359(1447):111725. https://doi.org/10.1098/rstb.2004.1483.

8. Kim HJ, Park HR. Factors affecting post-traumatic stress of general hospital nurses after the epidemic of Middle East respiratory syndrome infection. J Korean Clin Nurs Res. 2017;23(2):179-88.

9. Jung H, Kim J, Jeong S. Factors affected with post-traumatic stress in nurses involved in direct care for Middle East respiratory syndrome patients. Health Soc Welf Rev. 2016;26(4):488-507.

10. Johnson SU, Ebrahimi OV, Hoffart A. PTSD symptoms among health workers and public service providers during the COVID-19 outbreak. PLoS ONE. 2020;15(10):e0241032. https://doi.org/10.1371/ journal.pone.0241032.

11. Zheng R, Zhou Y, Fu Y, Xiang Q, Cheng F, Chen H, et al. Prevalence and associated factors of depression and anxiety among nurses during the outbreak of COVID-19 in China: A cross-sectional study. Int J Nurs Stud. 2020;114:103809. https://doi.org/10.1016/j.ijnurstu.2020.103809.

12. Kwon DH, Hwang J, Cho YW, Song ML, Kim KT. The Mental Health and Sleep Quality of the Medical Staff at a Hub-Hospital against COVID-19 in South Korea. J Sleep Med. 2020;17(1):93-7.

13. Eun HJ, Kwon TW, Lee SM, Kim TH, Choi MR, Cho SJ. A study on reliability and validity of the Korean version of impact of event scale-revised. J Korean Neuropsychiatr Assoc. 2005;44(3):303-10.

14. Labrague LJ, De Los Santos JAA. COVID-19 anxiety among front-line nurses: Predictive role of organisational support, personal resilience and social support. J Nurs Manag. 2020;28(7):1653-61. https://doi.org/10.1111/jonm.13121.

15. Shahrour G, Dardas LA. Acute stress disorder, coping self-efficacy and subsequent psychological distress among nurses amid COVID-19. J Nurs Manag. 2020;28(7):1686-95. https://doi.org/10.1111/ jonm.13124.

16. Chen CS, Wu HY, Yang P, Yen CF. Psychological distress of nurses in Taiwan who worked during the outbreak of SARS. Psychiatr Serv. 2005;56(1):76-9. https://doi.org/10.1176/appi.ps.56.1.76.

17. Fong IW. Emerging animal coronaviruses: first SARS and now MERS. Emerging Zoonoses. 2017;6380. https://doi.org/10.1007/978-3-319-50890-0_4.

18. Corley A, Hammond NE, Fraser JF. The experiences of health care workers employed in an Australian intensive care unit during the H1N1 Influenza pandemic of 2009: a phenomenological study. Int J Nurs Stud. 2010;47(5):577-85. https://doi.org/10.1016/j.ijnurstu.2009.11.015.

19. Purcell SR, Kutash M, Cobb S. The relationship between nurses' stress and nurse staffing factors in a hospital setting. J Nurs Manag. 2011;19(6):714-20. https://doi.org/10.1111/j.1365-2834.2011.01262.x.

20. Donnelly E. Work-related stress and posttraumatic stress in emergency medical services. Prehosp Emerg Care. 2012;16(1):76-85. https://doi.org/10.3109/10903127.2011.621044. 
21. Mo Y, Deng L, Zhang L, Lang Q, Liao C, Wang N, et al. Work stress among Chinese nurses to support Wuhan in fighting against COVID-19 epidemic. J Nurs Manag. 2020;28(5):1002-9. https://doi.org/10. 1111/jonm.13014.

22. Aiken LH, Clarke SP, Sloane DM, Sochalski J, Silber JH. Hospital nurse staffing and patient mortality, nurse burnout, and job dissatisfaction. JAMA. 2002;288(16):1987-93. https://doi.org/10.1001/jama. 288.16.1987.

23. Halcomb E, McInnes S, Williams A, Ashley C, James S, Fernandez R, et al. The experiences of primary healthcare nurses during the COVID-19 pandemic in Australia. J Nurs Scholarsh. 2020;52(5):553-63. https://doi.org/10.1111/jnu.12589.

24. Ehrlich H, McKenney M, Elkbuli A. Protecting our healthcare workers during the COVID-19 pandemic. Am J Emerg Med. 2020;38(7):1527-8. https://doi.org/10.1016/j.ajem.2020.04.024.

25. Lim EC, Seet RC, Lee KH, Wilder-Smith EP, Chuah BY, Ong BK. Headaches and the N95 face-mask amongst healthcare providers. Acta Neurol Scand. 2006;113(3):199-202. https://doi.org/10.1111/j. 1600-0404.2005.00560.x.

26. Mealer ML, Shelton A, Berg B, Rothbaum B, Moss M. Increased prevalence of post-traumatic stress disorder symptoms in critical care nurses. Am J Respir Crit Care Med. 2007;175(7):693-7. https://doi. org/10.1164/rccm.200606-735OC.

Publisher's Note Springer Nature remains neutral with regard to jurisdictional claims in published maps and institutional affiliations.

Da-Jeong Moon MPH, is a nurse in Chosun University Hospital, GwangjuRepublic of Korea.

Mi Ah Han MD, PhD, is a professor in the Department of Preventive Medicine, College of Medicine, Chosun University, Gwangju, Republic of Korea.

Jong Park MD, PhD, is a professor in the Department of Preventive Medicine, College of Medicine, Chosun University, Gwangju, Republic of Korea.

So Yeon Ryu MD, PhD, is a professor in the Department of Preventive Medicine, College of Medicine, Chosun University, Gwangju, Republic of Korea. 